\title{
The Congruence of Nurses in a Czech Hospital with Organizational Work Setting as Related to Organizational Engagement and Perceived Chances to Fulfill One's Own Professional Aspirations
}

\author{
Havrdova Zuzana $^{1} \&$ Simona Krupkova ${ }^{1}$ \\ ${ }^{1}$ Department of management and supervision in social and health organizations, Faculty of humanities, Charles \\ University in Prague, Czech Republic \\ Correspondence: Havrdova Zuzana, Department of management and supervision in social and health \\ organizations, Faculty of humanities, Charles University in Prague, FHS UK, Machova 7, 12300 Prague 2, Czech \\ Republic. E-mail: havrdova@fhs.cuni.cz
}

\author{
Received: September 10, 2013 Accepted: October 8, 2013 Online Published: October 11, 2013 \\ doi:10.5539/res.v5n5p73 \\ URL: http://dx.doi.org/10.5539/res.v5n5p73
}

\begin{abstract}
The aim of this study was to study how organizational engagement (OE) of nurses is related to the congruence with the work settings as described by the Worklife Model (Leiter \& Maslach 2004) and how the perceived lack of support in the relational aspect of the nurses' professional role (PRF) is related to the value-fit with the organization. Our concept of $\mathrm{OE}$ is concerned more with the employees' involvement in organizational goals than with their psychological state of mind. A non-experimental survey design was used to test the hypothetical relationships. From the population of 836 nurses at a Czech district hospital, 411 nurses were chosen by stratified selection. A response rate $83 \%$ was achieved with respect to the administered questionnaires.

There is a strong relationship between OE and total AWS score $(0.373, p<0.01)$, which supports our hypothesis. The level of autonomy of nurses, expressed by feeling of control over their job activities, has a very strong relationship with $\operatorname{OE}(0.418, p<0.01)$. The regression model proved the strong predictive power of value-fit and autonomy in the worklife for OE of nurses. The perceived lack of support in the relational aspect of the nurses' professional role has the highest correlation with workload, followed by value-fit and fairness. The model did not prove that PRF is significantly contributing to the value-fit between nurse and the organization. Furthermore, there is no association between PRF and OE. The implications for the management of quality process are discussed.
\end{abstract}

Keywords: engagement, person-centered care, value-fit, work-life model, professional role of nurse, quality management

\section{Introduction}

The Czech health care system has been undergoing many changes since 1990 when the communist regime ended (Kinkorová \& Topolčan, 2012). As in other Western countries, there are growing productivity pressures and financial concerns combined with low wages and lack of clinical supervision in Czech hospitals; taken together, these factors result in a considerably stressful environment for Czech nurses. As a result, there is growing dissatisfaction among Czech nurses. In an extensive research study on Czech nurses working in hospitals, Vévoda et al. (2010) identified several factors contributing to their work satisfaction, including proper salary, nature of care for patients, safety of job position and recognition of their results. Krupková and Havrdová (2013) assessed the satisfaction of nurses in a large Czech hospital based on the possibility to fulfill their professional role. Their result supports the view that Czech nurses view direct care for patients which involves a holistic approach to patients' needs as the most important (but significantly less supported) aspect of their professional role (as related to the other attributes of professionalism, i.e., work based on standards and on the nursing plan, etc.). This can mirror the fact that the quality issues in hospitals are seen to be related much more to a standardized and evidence-based approach to patients and less to the nurturing relationship which is often expected by patients. Similar to other countries, Czech nurses are forced to adopt the rather impersonal technocratic nature of care in their professional role; at the same time, however, responsivity to patients' needs is required (Epstein et al., 2005). For example, recognition of the importance of approaching the patient as a whole 
person, as expressed in the concept of person-centered care (e.g., Epstein et al., 2005), has become part of the ethical standards for Czech nurses (Česká asociace sester, 2008). As in other countries, this concept has been identified in the education of nurses as an important competency necessary for healthcare professionals. This situation can create confusion between the ideal concept of the nurse's professional role and the reality in which the role must be fulfilled.

In the present study we will look at how the lack of support in the relational aspect of nurses' professional role is related to the engagement for quality and change in the organization and, furthermore, how the lack of support is related to the congruence of nurses with the work settings as described by the Worklife Model (Leiter \& Maslach, 2004).

\section{Area Description}

\subsection{Engagement for Change and Quality Issues}

The concept of engagement has undergone rapid development in the last 15 years. The concept was first related to burnout (as the opposite of burnout) as an energetic state of involvement with activities that enhance one's sense of professional efficacy (Leiter \& Maslach, 2000). However, as Simpson (2009) and Bargagliotti (2012) have summarized, other modes of understanding this concept have also developed. Simpson (2009) conducted the following four distinctive lines of research on engagement: personal engagement, mentioned burnout/engagement, work engagement, and employee engagement. The most frequently researched concept of work engagement is psychological in nature and refers to a positive, fulfilling, work-related state of mind characterized by vigor, dedication, and absorption (Schaufeli et al., 2002). Laschinger and Leiter (2006), however, suggested that this alternative approach contributes very little additional explained variance to the concept of burnout.

Our concept of engagement is seen as more functional than psychological and we call it organizational engagement (OE). It is bound to the active involvement of employees in the quality development in the organization. The need for this concept is bound to the changes in the Czech health and social system. Such changes result in a high level of pressure among nurses and social workers on all levels of the organizations as new approaches and ideas must be discussed, administered, and implemented in day-to-day life at work. Furthermore, such pressure elicits various types of reactions. Voluntary engagement is useful for the management (which introduces the changes) because it legitimizes the process. However, there is very little research on what such engagement depends on. The concept means a proactive attitude of nurses regarding externally introduced pressure, which results in the provision of extra time and energy for issues related to the quality of care in their wards. We suppose that such engagement depends predominantly on the space for autonomy which nurses are able to create in an organization, and secondly on value-fit with the specific organization. We would also expect the nurses' professional ambitions to have some impact on the nature of care, which can contribute to the level of value-fit and thus to the OE.

To summarize, $\mathrm{OE}$ will be understood in this study as the attitude and disposition to proactively engage in organizational changes focused on higher quality of care, to bring one's own ideas for change, to learn new ways of behavior, and to be involved in discussion with the management regarding the quality of care. The concept was operationalized in the framework of the research studies which were conducted in Czech hospitals and social agencies by our university department.

\subsection{The Concept of Congruence with Organizational Setting}

Maslach and Leiter (1997) identified six areas of the work environment that are relevant to the relationships people develop with their work. The components identified include manageable workload and a sense of control of one's own work, opportunity for reward, a feeling of community, faith in the fairness of the workplace, and shared values. The quality of work-life in terms of these six factors can be assessed using a tool called the Areas of Worklife Survey (AWS).

According to Leiter \& Maslach, shared work environment can make the difference between burnout and engagement with work and also has an impact on turnover intention (Leiter \& Maslach, 2009). AWS was used in a Canadian program known as Civility, Respect, and Engagement in the Workplace (CREW), which was designed to reduce burnout and increase engagement in organizations.

In his review on engagement, Simpson (2009) recognized Leiter and Maslach's Worklife Model as one of the three most useful models for conceptualizing and measuring an employee's work environment. Simpson also points to the fact that the complexity of the work environment variable is such that there are other important 
work environment variables which are not included in the developed models; therefore, nurse researchers should not limit the work environment only to the established models.

Several studies have shown that AWS mirrors differences in the Czech organizational settings and can be a useful measure for further communication with employees and the development of organizational support systems in the Czech environment (Havrdová \& Šolcová, 2012) (Note 1). In a previous study on nurses and social workers in elderly care homes that utilized AWS (Havrdová \& Šafr, 2010), we concluded that the aspect of shared value, which was predicted particularly by reward and fairness in that sample, depends on how the organization realizes its mission to support its clients instead of just supporting itself. We felt that there is more underlying the component of values that should be taken into consideration in future research. Although in the present research we continue to use the AWS model (with a minor correction in the control dimension), we explore further the value-fit dimension by focusing on support of the relational aspect of the professional role of nurses. We also want to examine how the congruence with the organizational setting, which has been proven to correlate with work engagement, is related to the $\mathrm{OE}$ as we believe the results will be of interest among the Czech managers of quality in the hospitals.

\subsection{Professional Aspirations of Nurses and Chances for Fulfillment}

Nursing is a profession which prides itself on helping others and is focused on high-quality patient care. The focus on patients is an important value for nurses. In some studies, patient care has been found as the most important factor that increases nurses' job satisfaction (McNeese-Smith, 1999). Perry (2005) found that nurses who believe they provide high-quality care and have a strong connection to patients are the most satisfied with their career. Good relationships with patients in which nurses have a strong human connection with patients have a significant impact on job satisfaction (Jackson, 2005). There is also some evidence that providing person-centered care is associated with nurses' satisfaction with their jobs (Stewart et al., 2000). Some predictors of job satisfaction include the importance of a practice environment that enables nurses to fulfill their expectations (Smith et al., 2005). This may contribute to their satisfaction through supporting their need for autonomy and competency as defined in the self-determination theory (Van den Broeck et al., 2008).

If they can be fulfilled, the professional aspirations of nurses are a potential factor that can contribute to the value-fit with the concrete organization; if they are frustrated, however, they can make the value-fit lower.

\section{Methods}

\subsection{Aim}

Our aim is to test the hypothetical relationship between AWS and OE as well as how the value-fit could be influenced by professional role frustration (PRF).

We propose the following hypotheses in this study:

A. The level of OE is predicted by the level of work-life congruence, particularly by autonomy (feeling of control over their job activities) and congruence in values.

B. The professional role frustration negatively contributes to the level of value-fit between nurses and their work environment.

\subsection{Design and Sample}

A non-experimental survey design was used to test the hypothetical relationships. Ethical approval was received from two participating bodies - the scientific department of the faculty where the authors stay and the hospital quality management department of the district hospital, where the research was done (Note 2).

The sample of nurses used in this study was chosen by stratified selection. Four wards of a large district general hospital were intentionally chosen so that they represent the main aspects of professional fields of nursing in this hospital where nurses provide regular inpatient care. The representative categories chosen were intensive vs. standard care and surgical vs. internal fields. Therefore, the four selected departments were as follows: surgical intensive care department, surgical standard care department, internal intensive care department, and internal standard care department. All of the nurses who were on shift at these departments in the period of two weeks when the surveys were administered, were included in this study.

This hospital is engaged in quality management changes and its management was motivated to obtain free anonymous results from this research. One of the authors was simultaneously a student participating in the scientific activities of the university department and a quality manager at this hospital. 
The population of nurses working in this hospital consisted of 836 nurses. The total number of questionnaires administered to the selected wards was 411 . Out of these 411 questionnaires, 341 were returned (response rate $=$ $83 \%)$. The final sample after filtering those which were not filled in properly was $331(81 \%)$.

Table 1. Response rate of questionnaires according to the wards

\begin{tabular}{cc}
\hline Departments & Response rate \\
\hline Internal intensive care & 76 questionnaires $(76 \%)$ \\
Surgical intensive care & 96 questionnaires $(92 \%)$ \\
Internal standard care & 70 questionnaires $(67 \%)$ \\
Surgical standard care & 89 questionnaires $(86 \%)$ \\
\hline
\end{tabular}

The sample consisted mainly of women (99\%). Nearly half (48\%) of them were between the age of 25 and 35 years old. With respect to educational level, the majority had received a high school education and/or studied a specialization course after high school (73\%); only 14\% had a university degree. The length of praxis modus has been 10-20 years (38\%). Most respondents worked as registered nurses without supervision (93\%); furthermore, $9 \%$ of the nurses were in a leading position at the wards (head nurses).

\subsection{Data Collection}

Data were collected by means of two questionnaires which were administered in the wards through the head nurses. The head nurses were individually instructed how to administer it. Both of the questionnaires were placed into one envelope along with an explanation regarding the aim and meaning of the research and instructions on how to complete and return it to the researcher. After completing the questionnaire, the respondent placed it in the envelope, sealed it, and then anonymously deposited it into a box located in the ward. This protected the anonymity of respondents and also enabled the researchers to identify the ward where each respondent worked. The researchers expected there would be differences between the wards with respect to various aspects of worklife.

\subsubsection{Organizational Engagement (OE)}

According to the concept explained above, OE was operationalized with five items which mirror the overall tendency to be actively involved in the changes of quality in their ward, e. g., "As an employee I am interested in being engaged with the proposal for changes which influence the quality of my work." and "I share proposals with my boss which can lead to better quality of care." Participants rated their agreement with each of the items on a scale from 1 ("totally disagree") to 5 ("totally agree").

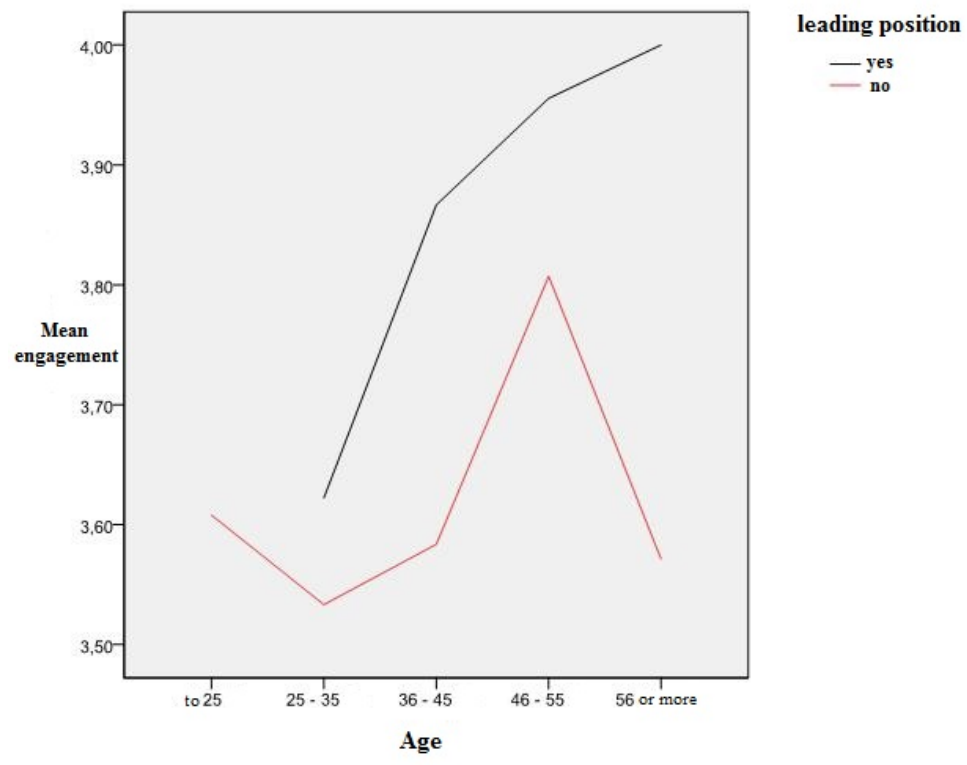

Figure 1. Organizational engagement according to age and leading position

Source: Working environment and role of nurse 2012, $\mathrm{N}=331$ 
Cronbach's $\alpha$ of this measure was .649.

We did not find any differences in OE depending on the ward or other demographic factors. The average score was 3.6. The only factors of the sample which influenced OE were age and leading position, as illustrated in Figure 1. We can see how the OE differs between those who are in a leading position and those who are not. In both groups the engagement grows with age, but at a certain point (around 55 years), unless the person is in a leading position, it drops radically.

\subsubsection{Congruence with Organizational Setting}

We used the AWS questionnaire with a minor adaptation of the dimension of control in which we added one item. This item was as follows: "I can influence the quality of work at my department with my suggestions." The reason for this minor correction was that the dimension of control consisted of only three items in comparison to other dimensions which relied on five or six items, and also because there was a repeatedly low Cronbach's $\alpha$ of this component in the Czech sample. This was already mentioned in our previous studies (e.g., Cronbach's $\alpha=$ 0.495 in Havrdová \& Šolcová, 2012).

The whole questionnaire thus consists of 30 items, and participants rated their agreement with each of the items on a scale from 1 ("totally disagree") to 5 ("totally agree"). Some items were reverse coded and then an average value was determined for each of the six areas of worklife. The higher the score, the greater the congruence with the work environment was. The total AWS score distribution in our sample was close to normal (Figure 2).

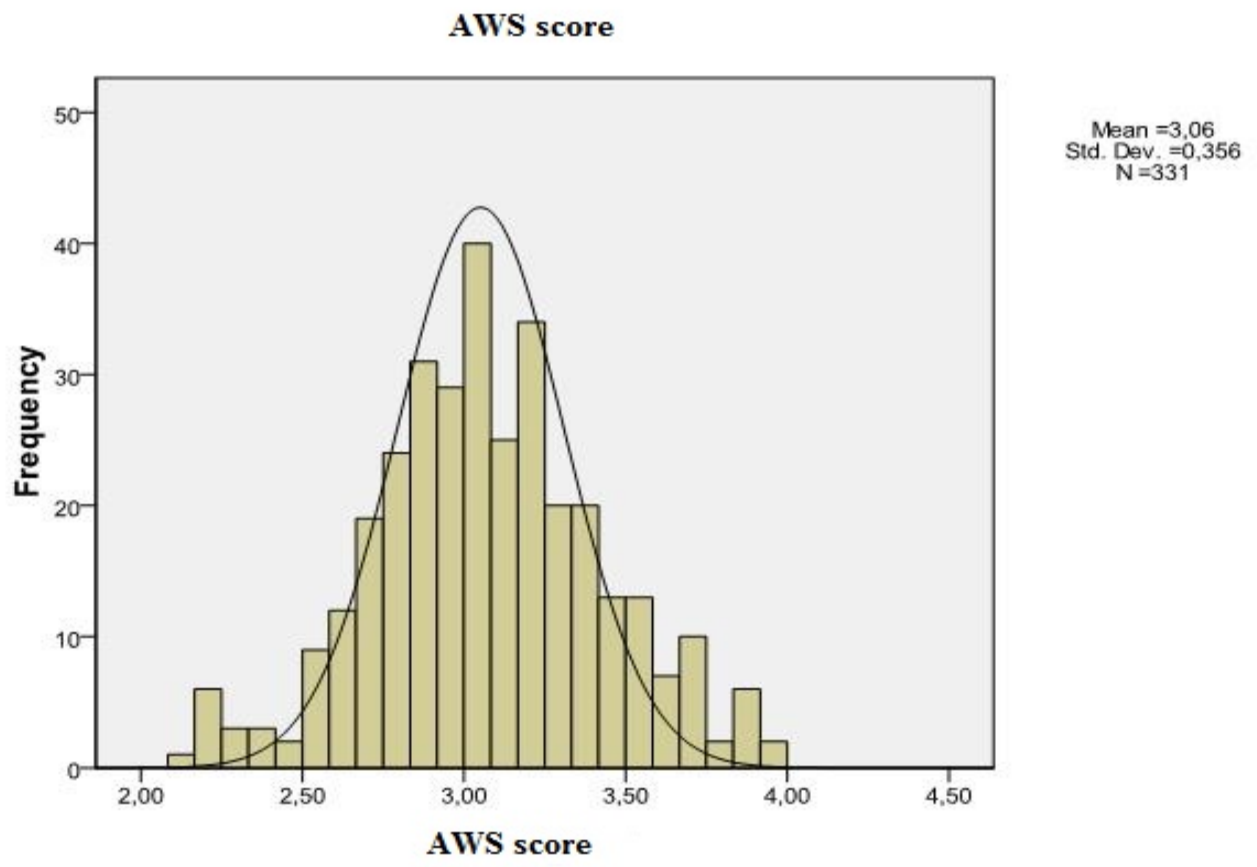

Figure 2. The total AWS score

Source: Working environment 2012, $\mathrm{N}=331$

The tipping point for counseling or management changes, according to Maslach (2011), is a mismatch in at least one area of worklife. In our sample we did not find significant differences in the average score in any of the six areas either between the wards or between the Czech and Canadian sample of nurses (Table 2). The average score for the Canadian sample in Leiter and Maslach's (2009) study are in brackets. 
Table 2. Average rating work areas

\begin{tabular}{lccccc}
\hline Area & IC int. & IC surg. & Dep. int. & Dep. surg. & Total $\varnothing$ \\
\hline Workload & 2.8 & 2.9 & 2.7 & 2.8 & $2.8(2.83)$ \\
Control & 3.1 & 3.1 & 3.2 & 3.2 & $3.2(3.35)$ \\
Rewards & 3.0 & 3.0 & 3.0 & 3.1 & $3.0(3.06)$ \\
Community & 3.7 & 3.7 & 3.4 & 3.5 & $3.6(3.46)$ \\
Fairness & 2.7 & 2.8 & 2.7 & 2.8 & $2.8(2.83)$ \\
Values & 3.3 & 3.1 & 3.1 & 3.2 & $3.2(3.43)$ \\
\hline
\end{tabular}

Source: Working environment 2012, N $=331$

The Cronbach's $\alpha$ in this Czech sample for the control dimension is 0.56 as compared to earlier when it was 0.495 (Havrdová \& Šolcová, 2012); the overall Cronbach's $\alpha$ for the AWS score is 0.827 .

Although in our earlier study the factor of higher education exerted some influence which showed higher congruence with control, reward, and value (Havrdová \& Šolcová, 2012), in this sample we did not find any such consistent relationship between factors characterizing the sample.

\subsubsection{Professional Aspirations}

The professional aspirations of nurses were conceptualized rather generally by means of a checklist of 11 role attributes, which represented the following two main aspects of the role: the direct contact with the patient and care for his/her bio-psycho-spiritual needs and other professional attributes resulting from the requirements of standards and health laws (for example, work according to the nursing plan or professional discretion).

The checklist was used for two sets of answers. First, the nurse decided on a 7-point scale $(1=$ least and $7=$ most $)$ what importance she ascribes personally to each item with respect to her professional role. Second, she decided on a 7 -point scale $(1=$ least and $7=$ most $)$ the degree to which her work environment in reality enables her to fulfill the referred aspect of her role. The difference between ascribed significance for her professional role and her belief regarding whether or not she can realize it in practice has been considered for further analysis.

In a previous study (Krupková \& Havrdová, 2013) the authors found that only those items from the checklist connected with "direct contact with patient" show a significant difference between the level of aspirations and the chance for those aspirations to be fulfilled (Figure 3).

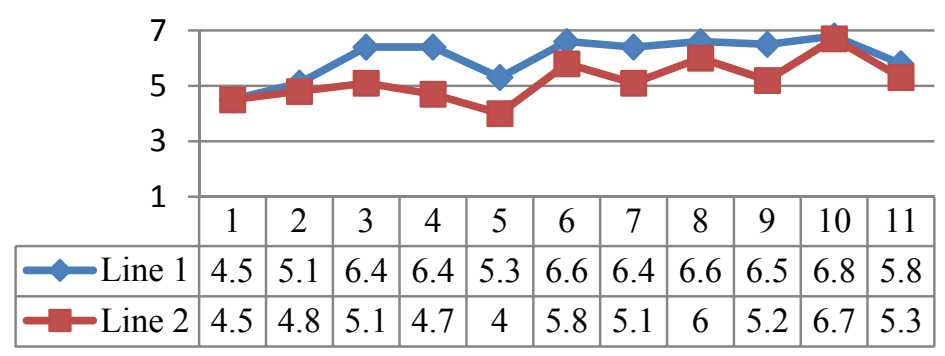

Figure 3. Comparison of the values of the role of the nurses in total

Source: Role of nurse 2012, N=331

Legend:

Line $1=$ perception of the importance of the role

Line 2 = possibility of realization in practice

In this study we consider the difference in "direct contact" items (3-9) as one scale. The Cronbach's $\alpha$ for this scale, which we called Professional Role Frustration (PRF), is 0.87 .

Some examples of the items which are used to count the difference are as follows: "To create an environment for the patient to satisfy his psychological needs"; "To always find the willingness to listen to the patient"; and "To be able to use communication to soothe difficult patients."

The score of difference between how important the nurse considers each item for her professional role and the extent to which the environment enables her to fulfill her aspirations represents a factor which, according to our 
hypothesis, can contribute to the value-fit as well as to the overall congruence of the employee with the organization. The meaning of this factor can be explained as a mark of the gap between the professional aspirations of nurses in relation to a highly human approach to patients - including good, kind, and professionally effective communication and a holistic approach to the patient as a human being - and how this kind of behavior and attitude can be realized in the concrete working environment in the ward of a hospital. The score on the scale will be higher if the average ascribed significance of the direct contact items by the individual nurse is higher and, at the same time, she believes her environment does not allow her to behave in a way she thinks is professionally appropriate.

\section{Results}

\subsection{Test of Hypothesis A}

To test hypothesis A ("The level of organizational engagement is predicted by the level of worklife congruence, particularly by autonomy (feeling of control over her job activities) and congruence in values"), we looked first at the bi-variate crosstabulation relationships between all factors. Since there were some promising relationships which appeared linear, we counted the Pearson correlation coefficient between variables.

Table 3. Correlations between organizational engagement and dimensions of AWS

\begin{tabular}{llrrrrrr}
\hline & Workload & Control & Reward & Community & Fairness & Values \\
\hline O-E & Pearson Correlation & .077 & $* * * .418$ & .214 & .197 & .238 & $* * .296$ \\
& Sig. (2-tailed) & .161 & .000 & .000 & .000 & .000 & .000 \\
$\mathrm{~N}$ & 331 & 331 & 331 & 331 & 331 & 331 \\
\hline Source: Role of nurse 2012, N=331, & $* p<0.10$ & $* *$ & $\mathrm{p}<0.05$ & $* * * \mathrm{p}$ & $<0.01$ &
\end{tabular}

There is a strong relationship between OE and total AWS score $(0.373, \mathrm{p}<0.01)$, which supports our hypothesis. The level of autonomy of nurses, expressed by feeling of control over her job activities, has a very strong relationship with OE $(0.418, \mathrm{p}<0.01)$. Although still significant, there is a weaker relationship between the value-fit and $\mathrm{OE}$ of nurses in this sample $(0.296, \mathrm{p}<0.05)$.

To approve the linearity of the relationship between OE and the two dimensions of AWS, a linear regression analysis was conducted, taking into consideration the possible influence of age and environmental differences in the four wards in the sample.

Table 4. Regression analysis organizational engagement parameter estimates

95\% Confidence Interval

Estimate Std. Error Ward df Sig. Lower Bound Upper Bound

\begin{tabular}{|c|c|c|c|c|c|c|}
\hline \multicolumn{2}{|c|}{ Threshold [OEngagement $\mathrm{REDUKCE}=1.00]$} & 4.600 & 1.00420 .984 & 1.000 & 2.632 & 6.567 \\
\hline & [OEngagement_REDUKCE $=2.00$ ] & 8.547 & 1.11259 .067 & 1.000 & 6.367 & 10.727 \\
\hline \multirow[t]{9}{*}{ Location } & Values_category & .795 & .24710 .326 & 1.001 & .310 & 1.280 \\
\hline & age & .198 & $.138 \quad 2.039$ & 1.153 & -.074 & 469 \\
\hline & Control_category & .860 & .20318 .011 & 1.000 & .463 & 1.257 \\
\hline & Community_category & .376 & 3.758 & $1 . \mathbf{0 5 3}$ & -.004 & .757 \\
\hline & Fairness_category & .308 & 2.445 & 1.118 & -.078 & .694 \\
\hline & [Ward_1 $=1.00]$ & .541 & 2.638 & 1.104 & -.112 & 1.193 \\
\hline & {$[$ Ward_1 $=2.00]$} & .607 & 2.982 & 1.084 & -.082 & 1.296 \\
\hline & {$[$ Ward_1 $=3.00]$} & .589 & 2.876 & 1.090 & -.092 & 1.270 \\
\hline & {$[$ Ward_1 $=4.00]$} & $0^{\mathrm{a}}$ & . & 0 . & & \\
\hline
\end{tabular}

Link function: Logit.

a. This parameter is set to zero because it is redundant. 
The regression model approved the strong predictive power of value-fit and autonomy in the worklife for the OE of nurses. Another parameter relevant to the OE in this model is community, which still weakly supports the linear relationships.

\subsection{Test of Hypothesis $B$}

To test hypothesis B ("The professional role frustration negatively contributes to the level of value-fit between nurses and their work environment"), the Pearson correlation coefficient for the relationship between the professional role frustration score and AWS dimensions was counted (Table 5).

Table 5 Correlations between professional role frustration and AWS

\begin{tabular}{|c|c|c|c|c|c|c|c|c|}
\hline & Workload & Control & Reward & Community & Fairness & Values & Engagement & $\begin{array}{c}\text { Engage4x } \\
\text { Engagementt } \\
(\mathrm{q} 31-35, \mathrm{CA} 0.72)\end{array}$ \\
\hline $\begin{array}{l}\text { PRF Pearson } \\
\text { Correlation }\end{array}$ & $-.224 * *$ & -.074 & -.164 & -.061 & $-.202 * *$ & $-.207 * *$ & .013 & ,121 \\
\hline Sig. (2-tailed) & 000 & .183 & .003 & .272 & .000 & .000 & .815 &, 031 \\
\hline $\mathrm{N}$ & 324 & 324 & 324 & 324 & 324 & 324 & 324 & 319 \\
\hline
\end{tabular}

Source: Role of nurse $2012, \mathrm{~N}=331, * * \mathrm{p}<0.05$

All correlations are negative and three of them are strong, reaching a 5\% level of significance. The highest correlation is between workload and PRF, followed by value-fit and fairness. This means there is a negative relation between PRF and three of the AWS dimensions.

The test of linearity in the linear regression model for values should have shown if PRF contributes significantly in the field of other relevant and previously described parameters of the worklife model to the value-fit (Table 6).

Table 6. Regression of dependent variable values

\begin{tabular}{|c|c|c|c|c|c|c|}
\hline \multirow[b]{2}{*}{ Mod } & & \multicolumn{2}{|c|}{ Unstandardized Coefficients } & \multirow{2}{*}{$\begin{array}{c}\text { Standardized } \\
\text { Coefficients }\end{array}$} & \multirow[b]{2}{*}{$\mathrm{t}$} & \multirow[b]{2}{*}{ Sig. } \\
\hline & & B & Std. Error & & & \\
\hline \multirow[t]{5}{*}{1} & (Constant) & 2.314 & .287 & & 8.052 & .000 \\
\hline & Fairness & .179 & .047 & .217 & 3.828 & .000 \\
\hline & Reward & .160 & .042 & .218 & 3.833 & .000 \\
\hline & PRF & -.059 & .044 & -.072 & -1.343 & .180 \\
\hline & Workload & -.038 & .043 & -.047 & -.887 & .376 \\
\hline
\end{tabular}

The regression model tested the relationship between values, fairness, reward, and PRF together with workload. However, the model did not prove that PRF is significantly contributing to the value-fit between nurses and the organization. The well described contribution of reward and fairness to the value-fit in the worklife model seems to be more robust than the influence of PRF and workload. Thus, although there is an important relationship between PRF and value-fit in terms of correlation, the negative contribution of PRF to value-fit seems not so dominant among other known factors in the worklife model. Furthermore, there is no association between PRF and $\mathrm{OE}$ (Pearson $\mathrm{CQ}=0.011$ ). We therefore could not prove hypothesis 2 .

\section{Discussion}

In the present study we wanted to examine how the engagement for quality and change in the organization is related to the congruence with the work settings as described by the Worklife Model (Leiter \& Maslach 2004) and how the perceived lack of support in the relational aspect of the nurses' professional role is related to the value-fit with the organization.

Our concept of engagement is concerned more with the involvement in organizational goals than with the psychological state of mind of the employee. It also has a more narrow meaning than the concept of engagement 
based on burnout as it is directly bound to the active involvement of the employee in the quality development in the organization. Our results show that nurses who are more engaged in the quality issues in the organization in our sample evaluate their own autonomy in the organization more positively, are inclined to see their own values as more congruent with the organizational values, and generally see their own congruence with the organization significantly more positively than the less engaged nurses.

The OE - engagement for quality - has the highest association with the perceived autonomy of nurses (the dimension of control in AWS), as was expected. The strong influence of control has already been demonstrated in Leiter's modified mediation model which shows a path from control through values to engagement (as the opposite of burnout) (Leiter \& Maslach, 2009). Instead of burnout/engagement, in this model we have directly used the items for OE. Similar to Leiter's model, our results also demonstrated the relatively strongest association with control, although it is not as strong as the association with burnout (Leiter \& Maslach, 2009). If we continue to compare the relationships of measured factors, there is also a difference in the position of values in relation to autonomy/control. Control in our sample only has a moderate correlation $(0.252, \mathrm{p}<0.05)$ to values and it does not emerge as an important factor in the regression model for values. The highest association in our sample is between control and OE. However, our results are representative only for one large Czech hospital. We might interpret this result as follows: in this particular hospital, the nurses' engagement in improving the quality of care depends largely on the degree to which they perceive the organization gives them space for their autonomy and, furthermore, this relationship is modified less by value-fit. This finding is also supported by the other results in our sample.

Our attempt to clarify another aspect of values and value-fit with the organization was not very successful. The value-fit dimension has shown only medium negative association with the professional role frustration $(-.207 * *$, $\mathrm{p}<0.05)$, and the value-fit has been determined more by rewards and community in AWS, which is already known from previous research, than by professional aspirations fulfillment. The support of the relational aspect of the professional role of nurses does not seem to have a very strong impact on overall congruence with the organization; furthermore, it has no association with their $\mathrm{OE}$ at all. We can say that in this sample, no association between quality engagement and aspirations to be supported in good relationships with patients exists, as represented in the PRF score. The PRF score is higher as the workload increases, which can be understood as follows: while lack of time has a direct impact on humanistic behavior in nurses' relationships with patients, it does not significantly determine the lower congruence in values and fairness with the organization. We may suppose that PRF mirrors some minor factors which contribute to values, but further research is necessary to clarify the relationship between values and the nature of support of the professional aspirations of nurses.

Data were collected only from one large Czech hospital and the results can be generalized only to this sample. However, we can see some similarities in the association of various factors in the working environment and needs of nurses which seem to have a more universal international character. The dimension of control in AWS seems to still have quite a low level of reliability; therefore, we need to look for some corrections in measuring this important dimension. There are a limited number of items which can be introduced to the research in the hospital as nurses are usually not willing to be involved in a broad and time-consuming research study. Therefore, we had to limit the scope of factors which could be followed in this research, despite the fact that the nature of relationships between the work environment, values, autonomy needs, and the nature of patient care are very complex. However, we think it will be meaningful to continue to study other aspects of values and professional aspirations of nurses, which are so crucial for the well-being of patients in the hospitals.

\section{Conclusion}

The concept of engagement has been conceptualized differently by a variety of previous researchers. We conceptualized $\mathrm{OE}$ in relation to quality management in a Czech republic as a proactive attitude among nurses toward changes in quality and their participation in the quality issues which are introduced by the management. The kind of engagement which was measured by OE items in this study was highly related to the congruence of nurses in the Czech hospital with their organizational work setting. The OE was related to all dimensions of the worklife model, which was similar to how the concept of engagement based on burnout, particularly with control and rewards, was understood in a previous study. However the $\mathrm{OE}$ was not directly associated with the proffessional aspiration of nurses to develop a humanistic approach to patient or person-centered care. Some indirect and subtle connections between these two factors were suggested only as mediated by value-fit with the organization. 
The more pronounced understanding of engagement in quality management as related to the humanistic aspects of care could be realized in practice through managers encouraging and rewarding the humanistic behavior of nurses, which, in turn, might contribute to improving nurses' identification with the organization and to the well-being of patients. As the OE of nurses in the hospital in this study is influenced more by perceived space for autonomy, rewards, and community than by value-fit or lack of support for the humanistic behavior of nurses, the focus of the rewards from management for the results of quality changes seems to be crucial.

\section{Acknowledgements}

This publication was supported by the the Ministry of Education, Youth and Sports - Institutional Support for Long-term Development of Research Organizations - Charles University, Faculty of Humanities (Charles Univ, Fac Human 2013).

\section{References}

Bargagliotti, A. L. (2012). Work engagement in nursing: A concept analysis. Journal of Advanced Nursing, 68(6), 1414-1428. http://dx.doi.org/ 10.1111/ j.1365-2648.2011.05859.x

Česká Asociace Sester. (2008). Etický kodex sester vypracovaný Mezinárodní radou sester. Retrieved from http://www.cnna.cz/docs/tiskoviny/eticky_kodex_icn.pdf

Epstein, R. M., Franks P., Fiscella, K., Shields, C. G., Meldrum, S. C., Kravitz, R. L., \& Duberstein, P. R. (2005). Measuring patient-centered communication in patient-physician consultations: Theoretical and practical issues. Social Science \& Medicine, 61, 1516-1528.

Havrdová, Z., \& Šafr, J. (2010). Kongruence v hodnotách jako ukazatel vztahů v péči o seniory. In Z. Havrdová et al., Hodnoty $v$ prostředi sociálních služeb (pp. 85-108). FHS UK v Praze, Praha. http://dx.doi.org/10.1016/j.socscimed.2005.02.001

Havrdová, Z., \& Šolcová, I. (2012). Work-place civility and mental health by helping professionals. In V. Olisah (Ed.), Essential Notes in Psychiatry (pp. 13-36). Rijeka: InTech.

Jackson, C. (2005). The experience of a good day: A phenomenological study to explain a good day as experienced by a newly qualified RN. International Journal of Nursing Studies, 42, 85-95. http://dx.doi.org/10.1016/j.ijnurstu.2004.05.015

Kinkorová, J., \& Topolčan, O. (2012). Overview of healthcare system in the Czech Republic. EPMA J., 3(1), 4. http://dx.doi.org/10.1007/s13167-012-0139-9

Krupková, S., \& Havrdová, Z. (2013). Napětí mezi přisuzovaným významem a možnostmi realizace pracovní role všeobecné sestry. Kontakt, 4 , in press.

Laschinger, H. K. S., \& Leiter M. P. (2006). The impact of nursing work environments on patient safety outcomes: The mediating role of burnout/engagement. Journal of Nursing Administration, 5, 259-267. http://dx.doi.org/10.1097/00005110-200605000-00019

Leiter, M. P., \& Maslach, C. (2000). Preventing burnout and building engagement: A complete program for organizational renewal. San Francisco: Jossey Bass. http://dx.doi.org/10.1111/j.1365-2834.2009.01004.x

Leiter, M. P., \& Maslach, C. (2004). Areas of worklife: A structured approach to organizational predictors of job burnout. In P. Perrewe, \& D. C. Ganster (Eds.), Research in occupational stress and well-being (Vol. 3, pp. 91-134). Oxford, United Kingdom: Elsevier.

Leiter M. P., \& Maslach, C. (2009). Nurse turnover: The mediating role of burnout. Journal of NursingManagement, 17, 331-339.

Maslach, C. (2011). Burnout and engagement in the workplace: New perspectives. The European Health Psychologist, 13(3), 44-47.

Maslach, C., \& Leiter, M. (1997). The truth about burnout. San Francisco: Jossey-Bass.

McNeese-Smith, D. K. (1999). A content analysis of staff nurse descriptions of job satisfaction and $\begin{array}{llll}\text { dissatisfaction. Journal of Advanced } & \text { Nursing, } & \text { 29, } & \text { 1332-1341. }\end{array}$ http://dx.doi.org/10.1046/j.1365-2648.1999.01018.x

Perry, B. (2005). Core nursing values brought to life through stories. Nursing Standard, 20, 41-48. http://dx.doi.org/10.7748/ns2005.10.20.7.41.c3985 
Schaufeli, W. B., Salanova, M., Gonzalez-Roma, V., \& Bakker, A. B. (2002). The measurement of engagementand burnout: A confirmative analytic approach. Journal of Happiness Studies, 3, 71-92. http://dx.doi.org/10.1023/A:1015630930326

Simpson, M. R. (2009). Engagement at work: A review of literature. International Journal of Nursing Studies, 46, 1012-1024. http://dx.doi.org/10.1016/j.ijnurstu.2008.05.003

Smith, H. L., Hood, J. N., Waldman, J. D., \& Smith, V. L. (2005). Creating a favorable practice environment for nurses. Journal of Nursing Administration, 525-532. http://dx.doi.org/10.1097/00005110-200512000-00006

Stewart, M., Brown, T. B., Donner, A., McWhinney, L. R., Oates, J., Weston, W. W., \& Jordan J. (2000). The impact of patient-centered care on outcomes. The Journal of Family Practice, 49(9), 796-804.

Van den Broeck, A., Vansteenkiste, M., de Witte, H., \& Lens, W. (2008). Explaining the relationships between job characteristics, burnout, and engagement: The role of basic psychological need satisfaction. Work \& Stress, 22(3), 277-294. http://dx.doi.org/10.1080/02678370802393672

Vevoda, J., Ivanova, K., Naklaalova, M., \& Mareckova, J. (2010). Pracovní spokojenost všeobecných sester. $\begin{array}{lllll}\text { Profese. } & \text { Retrieved } & \text { April } & \text { 23, } & \text { from }\end{array}$ http://profeseonline.upol.cz/pracovnispokojenost-vseobecnych-sester

\section{Copyrights}

Copyright for this article is retained by the author(s), with first publication rights granted to the journal.

This is an open-access article distributed under the terms and conditions of the Creative Commons Attribution license (http://creativecommons.org/licenses/by/3.0/). 